\title{
Exploring the potential effect of Ocimum sanctum in vincristine-induced neuropathic pain in rats
}

\author{
Gurpreet Kaur, Amteshwar Singh Jaggi, Nirmal Singh ${ }^{*}$
}

\begin{abstract}
The present study was designed to investigate the ameliorative potential of Ocimum sanctum and its saponin rich fraction in vincristine-induced peripheral neuropathic pain in rats. Peripheral neuropathy was induced in rats by administration of vincristine sulfate (50 $\mathrm{gg} / \mathrm{kg}$ i.p.) for 10 consecutive days. The mechanical hyperalgesia, cold allodynia, paw heat hyperalgesia and cold tail hyperalgesia were assessed by performing the pinprick, acetone, hot plate and cold tail immersion tests, respectively. Biochemically, the tissue thio-barbituric acid reactive species (TBARS), super-oxide anion content (markers of oxidative stress) and total calcium levels were measured. Vincristine administration was associated with the development of mechanical hyperalgesia, cold allodynia, heat and cold hyperalgesia. Furthermore, vincristine administration was also associated with an increase in oxidative stress and calcium levels. However, administration of Ocimum sanctum (100 and $200 \mathrm{mg} / \mathrm{kg}$ p.o.) and its saponin rich fraction (100 and $200 \mathrm{mg} / \mathrm{kg}$ p.o.) for 14 days significantly attenuated vincristine-induced neuropathic pain along with decrease in oxidative stress and calcium levels. It may be concluded that Ocimum sanctum has ameliorative potential in attenuating chemotherapy induced-painful neuropathic state, which may be attributed to decrease in oxidative stress and calcium levels. Furthermore, saponin rich fraction of Ocimum sanctum may be responsible for its noted beneficial effect in neuropathic pain in rats.
\end{abstract}

\section{Introduction}

Neuropathic pain has been described as "the most terrible of all tortures which a nerve wound may inflict" [1]. Despite progress in the understanding of this syndrome, the mechanistic details underlying the disease remain elusive. Neuropathic pain is generally characterized by the sensory abnormalities such as unpleasant abnormal sensation (dysesthesia), an increased response to painful stimuli (hyperalgesia), and pain in response to a stimulus that does not normally provoke pain (allodynia) [2]. Peripheral neuropathic pain is frequently observed in patients with cancer, AIDS, long standing diabetes, lumbar disc syndrome, herpes infection, traumatic spinal cord injury, multiple sclerosis and stroke [3]. Moreover, post-thoracotomy, post-herniorrhaphy, post-mastectomy and post-sternotomy are some other conditions often associated with peripheral neuropathy pain [4].

Chemotherapeutic drugs such as vincristine, paclitaxel, oxaliplatin, etc. are widely used in management of cancers especially Hodgkins lymphoma, non-Hodgkins

\footnotetext{
*Correspondence: nirmal_puru@rediffmail.com

Department of Pharmaceutical Sciences and Drug Research, Punjabi University, Patiala, India
}

lymphoma and leukemia. Unfortunately, these anti-cancer agents have been documented to produce dose and duration dependent neurotoxicity and painful neuropathy [5] which limit their full exploitation in the management of tumors. Vincristine is unique among the chemotherapeutic agents that it produces predictably and uniformly neurotoxicity in all the patients even at the therapeutic doses [6]. This peripheral neuropathy is dose-related with a marked variability in individual susceptibility. After stopping vincristine administration, partial or complete clinical recovery follows which takes several months.

Though some drugs have been found to be effective in managing the symptoms of neuropathy, yet their full clinical exploitation is limited due to wide spectrum of adverse effects associated with their clinical use. Moreover, none of the medications, assessed in randomized controlled studies conducted, has been found to be effective in injury induced and chemotherapy-induced neuropathic pain [7]. Therefore, there has been an urgent need of alternative medicine for managing neuropathy particularly in injury and chemotherapy-induced 
neuropathic pain, for which the best option may be to look back at the traditional medicines.

Ocimum sanctum (L.), (syn, Tulsi) is an indigenous plant commonly found in India and is recommended in the Ayurveda for the treatment of bronchial asthma, malaria, dysentery, skin diseases, arthritis, painful eye diseases, chronic fever and insect bite. Experimental reports have indicated its protective effects against genotoxicants, chemical carcinogens, ischaemic cerebral injury [8], ischaemia-reperfusion and isoproterenolinduced myocardial damage. Moreover, its anti-convulsant [9], hepato-protective, immuno-modulatory, antiulcer, anti-diabetic, anti-hypercholesterolaemic, chemoprotective, nootropic, antitussive, anti-inflammatory, wound healing, anti-tumorigenesis, anthelmintic, antibacterial, anti-giardial [10], anti-anxiety [11], and antistress activities have also been documented. Traditionally, Ocimum sanctum has been used as nerve tonic and to alleviate joint pain, headache and muscular pain particularly in South India. Recently, from our laboratory it has been documented that Ocimum sanctum has ameliorative potential in attenuating sciatic nerve transectioninduced neuropathic pain [12].

Saponins are important phyto-constituents present in different plants including Ocimum sanctum in which these constitute an important chemical class and include pentacyclic triterpenoids saponins such as ursolic acid, oleanolic acid $[13,14]$. Number of studies have shown that saponins exert diverse biological actions such as anti-hypertensive [15], anti-cancer [16], anti-convulsant [17], anti-diabetic [18], anti-amnestic [19], hypocholesterolaemic [20] and neuroprotective [21]. Furthermore, saponins have also been shown to exhibit anti-nociceptive actions [22,23]; alleviate neuropathic pain in long standing diabetes [24] and nerve entrapment induced facial paralysis (Bell's palsy) [25].

The present study was designed to investigate the ameliorative role of Ocimum sanctum in vincristineinduced neuropathy and to further explore the contributory role of saponins in Ocimum sanctum mediated beneficial effect in neuropathic pain in rats.

\section{Materials and methods}

\section{Experimental Animals}

Wistar albino rats weighing 180-250 g, maintained on standard laboratory diet (Kisan Feeds Ltd., Mumbai, India) and having free access to tap water were employed in the present study. They were housed in the departmental animal house and were exposed to normal cycle of light and dark. The experimental protocol was approved by the Institutional Animal Ethics Committee (IAEC) and the care of the animals was carried out as per the guidelines of the Committee for the Purpose of Control and Supervision of Experiments on Animals
(CPCSEA), Ministry of Environment and Forest, Government of India (Reg. No- 107/1999/CPCSEA).

\section{Drugs and Chemicals}

Vincristine sulfate (Chandra Bhagat Pharma Pvt. Ltd., Mumbai), was dissolved in normal saline. All the reagents used in the present study were of analytical grade.

\section{Plant material}

Fresh leaves of Ocimum sanctum were collected from Patiala and authenticated through Botany Department, Punjabi University, Patiala. The Plant sample has been kept in Voucher specimen (PUP-039/2008-2009) at Punjabi university, Patiala. The fresh leaves of Ocimum sanctum were shed dried at room temperature and reduced to coarse powder. The powder was extracted with mixture of methanol: water (3:1). The solvent was completely removed at $50^{\circ} \mathrm{C}$ under reduced pressure. The yield of the extract was $13 \%(\mathrm{w} / \mathrm{w})$ in terms of dried starting material. The extract was standardized using HPTLC finger-printing taking chloroform and methanol (80:20) as mobile phase and using anisaldehyde sulphuric acid as spraying agent. The bands were detected at $254 \mathrm{~nm}, 366$ $\mathrm{nm}$ and under white light (Table 1). The saponin rich fraction was extracted from the concentrated hydro-alcoholic extract as described earlier [26,27]. Briefly, the hydro-alcoholic extract was decanted by $n$-hexane followed by extraction with n-butanol. After three successive extractions with $\mathrm{n}$-butanol, the resulting solutions were combined and the butanol was completely removed at $50^{\circ} \mathrm{C}$ under reduced pressure to collect the residue rich in saponin. The saponins were identified using froth test and triterpenoid saponins were identified using Lieberman-Burchard test.

\section{Induction of Neuropathic Pain by Vincristine}

Peripheral neuropathy was induced in rats by administration of vincristine sulfate $(50 \mu \mathrm{g} / \mathrm{kg}$ i.p.) for 10 consecutive days as described previously [28].

\section{Behavioral Examination}

Paw Cold-Allodynia (Acetone Drop Test)

The cold allodynia was assessed by spraying a $100 \mu \mathrm{L}$ of acetone onto the planter surface of the paw, without touching the skin. The duration of withdrawal response was recorded with an arbitrary minimum value of $0.5 \mathrm{~s}$ and a maximum value of $20 \mathrm{~s}$ [29].

\section{Paw Heat-Hyperalgesia (Hot Plate Test)}

The thermal nociceptive threshold, as an index of thermal hyperalgesia, was assessed by the Eddy's hot plate, which is an instrument designed by Eddy and co-workers to assess thermal sensitivity. The plate was preheated and maintained at a temperature of $52.5 \pm 2.0^{\circ} \mathrm{C}$. 
Table 1 HPTLC fingerprinting of hydro-alcholic extract of Ocimum sanctum taking chloroform and methanol (80:20) as mobile phase and using anisaldehyde as spraying agent. The values indicate the $R_{f}$ values of the separated bands.

\begin{tabular}{llll}
\hline S. No of Resolving Bands & UV $\mathbf{2 5 4} \mathbf{~ n m}$ & UV $\mathbf{3 6 6}$ & Under white light \\
\hline 1. & - & - & 0.44 \\
\hline 2. & - & - & 0.60 \\
\hline 3. & - & - & 0.71 \\
\hline 4. & - & - & 0.78 \\
\hline 5. & - & - & 0.85 \\
\hline
\end{tabular}

The rat was placed on the hot plate and nociceptive threshold, with respect to licking of the hind paw, was recorded in seconds. The cut-off time of $20 \mathrm{~s}$ was maintained [30].

\section{Mechanical hyperalgesia: (Pin prick test)}

The mechanical hyperalgesia was assessed by the pinprick test as described by Erichsen and BlackburnMunro [31]. The surface of the injured hind paw was touched with the point of the bent gauge needle (at $90^{\circ}$ to the syringe) at intensity sufficient to produce a reflex withdrawal response in normal non-operated animals, but at an intensity which was insufficient to penetrate the skin. The duration of the paw withdrawal was recorded in seconds with a stopwatch. A cut-off time of $20 \mathrm{~s}$ was maintained.

\section{Tail Cold-Hyperalgesia Test (Tail Immersion Test)}

The tail cold-hyperalgesia was noted by immersing a terminal part of the tail $(1 \mathrm{~cm})$ in the water, maintained at a temperature of $0-4^{\circ} \mathrm{C}$. The tail withdrawal latency was recorded and a cut-off time of $20 \mathrm{~s}$ was maintained [32].

\section{Biochemical Estimation}

All the groups of animals were sacrificed after $14^{\text {th }}$ day by cervical dislocation and the sciatic nerve was isolated immediately $[30,33]$. The uniformity among the different nerve samples was maintained by taking the constant weight of the respective samples. The excised sciatic nerve homogenate $(10 \% \mathrm{w} / \mathrm{v})$ was prepared with $0.1 \mathrm{M}$ Tris- $\mathrm{HCl}$ buffer ( $\mathrm{pH}$ 7.4). The tubes with homogenate were kept in ice water for 30 minutes and centrifuged at $4^{\circ} \mathrm{C}$ (2500 rpm, $\left.10 \mathrm{~min}\right)$. The supernatant of homogenate was separated, and employed to estimate total protein content, TBARS, superoxide anion concenteration and total calcium content.

\section{Estimation of the protein content}

The protein concentration in the sciatic nerve was estimated according to the method of Lowry et al., [34] using bovine serum albumin as a standard. The absorbance was determined spectrophotometrically at 750 nm.

\section{Estimation of thio-barbituric acid reactive substances}

The estimation of lipid peroxidation in the sciatic nerve was done by measuring the thio-barbituric acid reactive substances by the method of Okhawa et al. [35]. The absorbance was measured spectrophotometrically at 532 $\mathrm{nm}$. The concentration was expressed in terms of nmol of thio-barbituric acid reactive substances/mg protein.

\subsubsection{Estimation of superoxide anion generation}

The superoxide anion generation in the sciatic nerve was estimated in terms of measuring reduced nitroblue tetrazolium (NBT) [36]. The absorbance of formazan was determined spectrophotometerically at $540 \mathrm{~nm}$.

\section{Estimation of total calcium}

The total calcium levels were estimated in the sciatic nerve as described earlier [33,37]. Briefly, the sciatic nerve homogenate was mixed with $1 \mathrm{ml}$ of trichloroacetic acid (4\%) in ice cold conditions and centrifuged at $1500 \mathrm{~g}$, for 10 minutes. The clear supernatant was used for the estimation of total calcium ion by atomic emission spectroscopy at $556 \mathrm{~nm}$.

\section{Experimental Protocol}

Nine groups, each group comprising six Wistar albino rats, were employed in the present study.

\section{Group I: Normal control group}

Rats were not subjected to any treatment and were kept for 14 days. The behavioral tests were employed on different days i.e., day $2^{\text {nd }}, 6^{\text {th }}, 8^{\text {th }}$ and $14^{\text {th }}$. All the animals were sacrificed at end of the $14^{\text {th }}$ day and the biochemical analysis was done for estimation of protein content, TBARS, superoxide anion and total calcium.

\section{Group II: Vincristine control group}

Vincristine $(50 \mu \mathrm{g} / \mathrm{kg}$, i.p. $)$ was administered to normal rats for 10 consecutive days (1-10). The behavioral tests were assessed starting on days $2^{\text {nd }}, 6^{\text {th }}, 8^{\text {th }}$ and $14^{\text {th }}$. At the end of $14^{\text {th }}$ day, the animals were sacrificed and biochemical analysis was done as described in group I.

\section{Group III: Vehicle in vincristine control group}

Rats were administered carboxymethylcellulose suspension $(0.5 \% \mathrm{w} / \mathrm{v}$, p.o. $) 2 \mathrm{~h}$ before each vincristine injection, for 14 consecutive days (1-14). The behavioral tests and biochemical parameters were assessed as mentioned in group I.

Group IV: Hydro-alcoholic extract of Ocimum sanctum per se

The hydro-alcoholic extract of Ocimum sanctum (200 $\mathrm{mg} / \mathrm{kg}$ p.o.) was administered to normal rats for 14 consecutive days, starting from the day one. The behavioral tests and the biochemical parameters were assessed as described in group I.

Group V: Saponin rich extract of Ocimum sanctum per se The saponin rich extract of Ocimum sanctum $(200 \mathrm{mg} /$ $\mathrm{kg}$ p.o.) was administered to normal rats for 14 consecutive days, starting from the day one. The behavioral 
tests and the biochemical parameters were assessed as described in group I.

Group VI and VII: Hydro-alcoholic extract of Ocimum sanctum (100; $200 \mathrm{mg} / \mathrm{kg}$ p.o.) in vincristine control group The hydro-alcoholic extract of Ocimum sanctum (100; $200 \mathrm{mg} / \mathrm{kg}$ p.o.) was administered for 14 consecutive days, starting from the day one, $2 \mathrm{~h}$ prior to vincristine administration. The behavioral tests and the biochemical parameters were assessed as described in group I.

Group VIII and IX: Saponin rich fraction of Ocimum sanctum (100; $200 \mathrm{mg} / \mathrm{kg}$ p.o.) in vincristine control group

The saponin rich fraction of Ocimum sanctum (100 and $200 \mathrm{mg} / \mathrm{kg}$ p.o.) was administered for 14 consecutive days, starting from the day one, $2 \mathrm{~h}$ prior to vincristine administration. The behavioral tests and the biochemical parameters were assessed as described in group I.

\section{Statistical Analysis}

All the results were expressed as mean \pm standard error mean (S.E.M.). The data of behavioral results was statistically analyzed by two-way ANOVA followed by Bonferonni's post test by using Graph pad prism Version5.0 software. The data of biochemical results was statistically analyzed by one-way ANOVA followed by Tukey's multiple range test by using Sigmastat Version2.0 software. The $p$-value $<0.05$ was considered to be statistically significant.

\section{Results}

Effect of Ocimum sanctum and its Saponin Rich Fraction on Cold Allodynia in Neuropathic Pain

Vincristine administration resulted in the development of cold allodynia as reflected by an increase in the duration of hind paw withdrawal, when compared to normal control group. However, pre-treatment with Ocimum sanctum (100 and $200 \mathrm{mg} / \mathrm{kg}$ p.o.) and its saponin rich fraction (100 and $200 \mathrm{mg} / \mathrm{kg}$ p.o.) significantly attenuated vincristine-induced increase in the withdrawal duration of the hind paw in response to non-noxious cold stimuli. The effect of saponin rich fraction in attenuating cold allodynia was significantly higher than the hydro-alcoholic extract at the same dose levels (Figure 1). Vehicle administration did not modulate the behaviour in response to non-noxious cold stimulus in animals subjected to peripheral neuropathy. Per se administration of Ocimum sanctum and its saponin rich fraction also did not produce alterations in the normal rats.

\section{Effect of Ocimum sanctum and its saponin rich fraction on mechanical hyperalgesia in Neuropathic Pain}

Vincristine administration was associated with the development of mechanical hyperalgesia as reflected by an increase in the hind paw withdrawal duration, when compared to normal control group. Treatment with
Ocimum sanctum (100 and $200 \mathrm{mg} / \mathrm{kg}$ p.o.) and its saponin rich fraction (100 and $200 \mathrm{mg} / \mathrm{kg}$ p.o.) significantly attenuated vincristine-induced increase in withdrawal duration of the hind paw in response to noxious mechanical stimuli. The effect of saponin rich fraction in attenuating mechanical hyperalgesia was significantly higher than the hydro-alcoholic extract at the same dose levels (Figure 2). Vehicle administration did not modulate behaviour in response to noxious mechanical stimulus in animals subjected to peripheral neuropathy. Per se administration of Ocimum sanctum and its saponin rich fraction also did not produce alterations in the normal rats.

\section{Effect of Ocimum sanctum and its saponin rich fraction} on paw heat and cold tail hyperalgesia in Neuropathic Pain

Vincristine administration led to the development of paw heat and tail cold hyperalgesia as reflected by decrease in the withdrawal threshold of the hind paw and tail respectively, when compared to normal control group. However, treatment with Ocimum sanctum (100 and $200 \mathrm{mg} / \mathrm{kg}$ p.o.) and its saponin rich fraction (100 and $200 \mathrm{mg} / \mathrm{kg}$ p.o.) significantly attenuated vincristineinduced decrease in the withdrawal latency in response to noxious thermal stimuli. The effect of saponin rich fraction in attenuating thermal hyperalgesia was significantly higher than the hydro-alcoholic extract at the same dose levels (Figures 3 and 4). Vehicle administration did not modulate behaviour in response to noxious thermal stimulus in animals subjected to peripheral neuropathy. Per se administration of Ocimum sanctum and its saponin rich fraction also did not produce alterations in the normal rats.

\section{Effect of Ocimum sanctum and its saponin rich fraction} on oxidative stress markers and total calcium content in Neuropathic Pain

Vincristine administration resulted in an increase in the oxidative stress markers and total calcium content as reflected by an increase in the tissue thio-barbituric acid reactive substances, superoxide anion content and total calcium levels, when compared to normal control group. However, treatment with Ocimum sanctum (100 and $200 \mathrm{mg} / \mathrm{kg}$ p.o.) and its saponin rich fraction (100 and $200 \mathrm{mg} / \mathrm{kg}$ p.o.) significantly attenuated the vincristineinduced increase in oxidative stress markers and total calcium levels. The effect of saponin rich fraction in attenuating the rise in the levels of oxidative stress markers and the calcium levels was significantly higher than the hydro-alcoholic extract at the same dose levels. Vehicle administration did not modulate alterations in the levels of oxidative stress markers and total calcium content in animals subjected to peripheral neuropathy. 


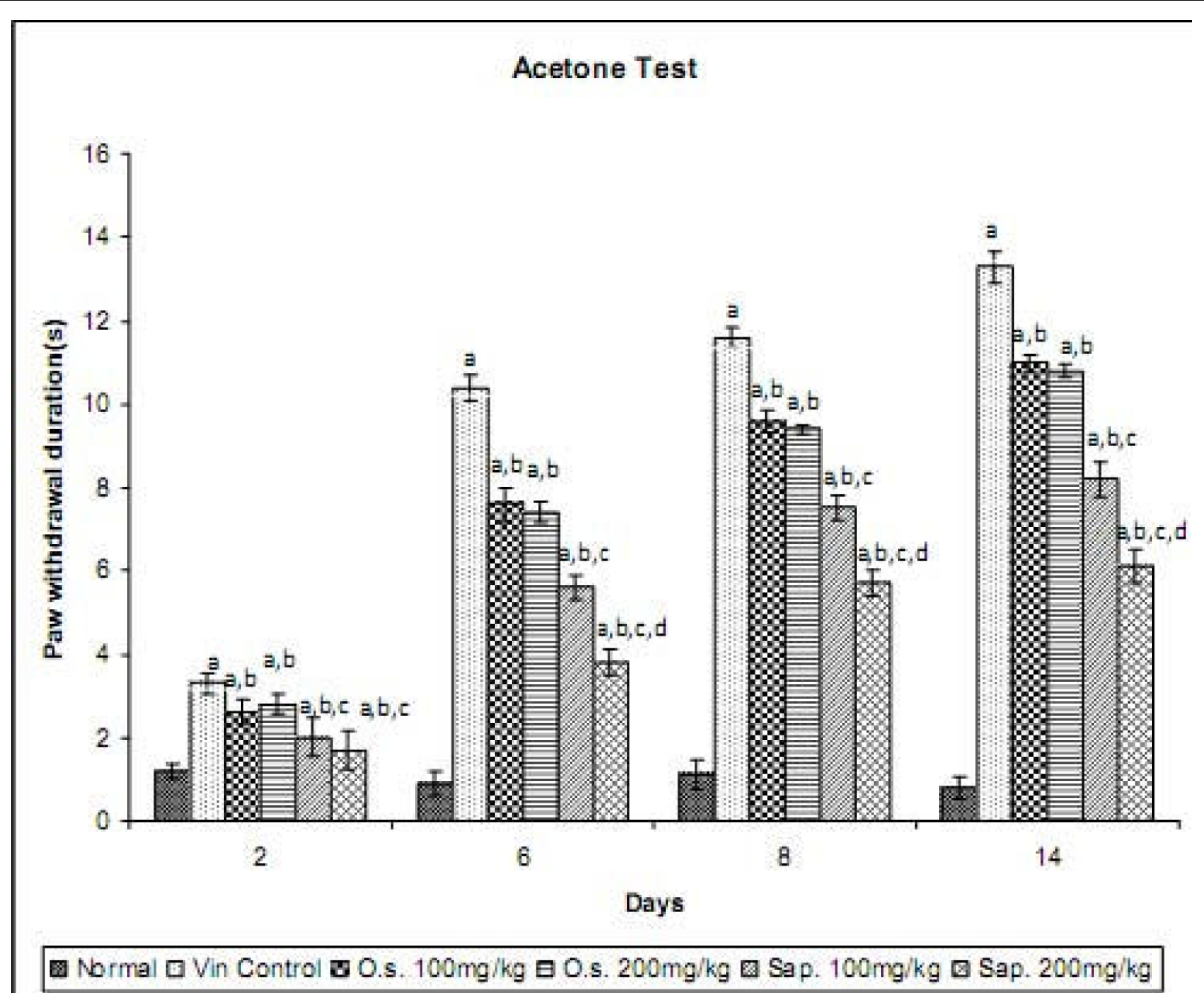

Figure 1 Effect of Ocimum sanctum and its saponin rich fraction on cold allodynia in vincristine-induced neuropathic pain. Vin: vincristine; O.s.: Ocimum sanctum; Sap.: saponin rich extract of Ocimum sanctum. Data were expressed as mean \pm S.E.M., $\mathrm{n}=6$ rats per group. a $=p<0.05$ Vs normal control group, $b=p<0.05$ Vs vincristine control group, $c=p<0.05$ Vs Ocimum sanctum 100 and 200 mg $/ \mathrm{kg}$ group, $d=$ $\mathrm{p}<0.05 \mathrm{Vs}$ saponin rich fraction $100 \mathrm{mg} / \mathrm{kg}$ group.

Per se administration of Ocimum sanctum and its saponin rich fraction also did not produce any biochemical alterations in the normal rats (Table 2).

\section{Discussion}

In the present investigation, vincristine $(50 \mu \mathrm{g} / \mathrm{kg}$, i.p. $)$ administration for 10 days led to significant development of cold allodynia, mechanical, tail cold and paw heat hyperalgesia. The observed behavioral alterations in this study are in consistent with the earlier reports documenting the development of pain symptoms with vincristine administration [28,33]. Vincristine has been widely employed for the management of number of cancers including Hodgkin's disease. However, its clinical application has been limited due to unavoidable painful sensorimotor neuropathy, observed in about half of the patients on vincristine treatment. Clinically, the neuropathy is characterized by paresthesias in hand and feet and the pinprick and thermal senses are more affected than vibration senses. Binding of vincristine to $\beta$-tubulin with subsequent disruption of microtubules has been documented for its anti-tumor actions and the same is also assumed to produce neuro-toxicity by axonal degeneration.
However, pretreatment with Ocimum sanctum significantly attenuated vincristine-induced alterations in pain perception in response to noxious as well as non-noxious stimuli, suggesting that Ocimum sanctum may be employed to limit the painful symptoms associated with chemotherapy treatment. Traditionally, Ocimum sanctum has been used as a nerve tonic to alleviate disorders related to nerves. Recently, it has been reported from our laboratory that Ocimum sanctum attenuates the neuropathic pain in sciatic nerve transection model [12].

Ocimum sanctum is a rich source of a number of saponins and the most important of them are ursolic acid and oleanolic acid. These saponins have been reported to possess beneficial effects in number of disorders such as in amnesia [38], hypertension [39], myocardial ischemia [40], and cancer [41]. Furthermore, the saponins have also shown the beneficial effects in relieving nociceptive pain $[22,23]$ as well as neuropathic pain in diabetes [24] and facial paralysis (Bell's palsy) due to nerve entrapment [25]. Therefore, to explore the chemical class of Ocimum sanctum responsible of its beneficial effect its saponin rich fraction was evaluated in neuropathic pain. In the present investigation, pre-treatment with the saponin rich fraction of Ocimum sanctum 


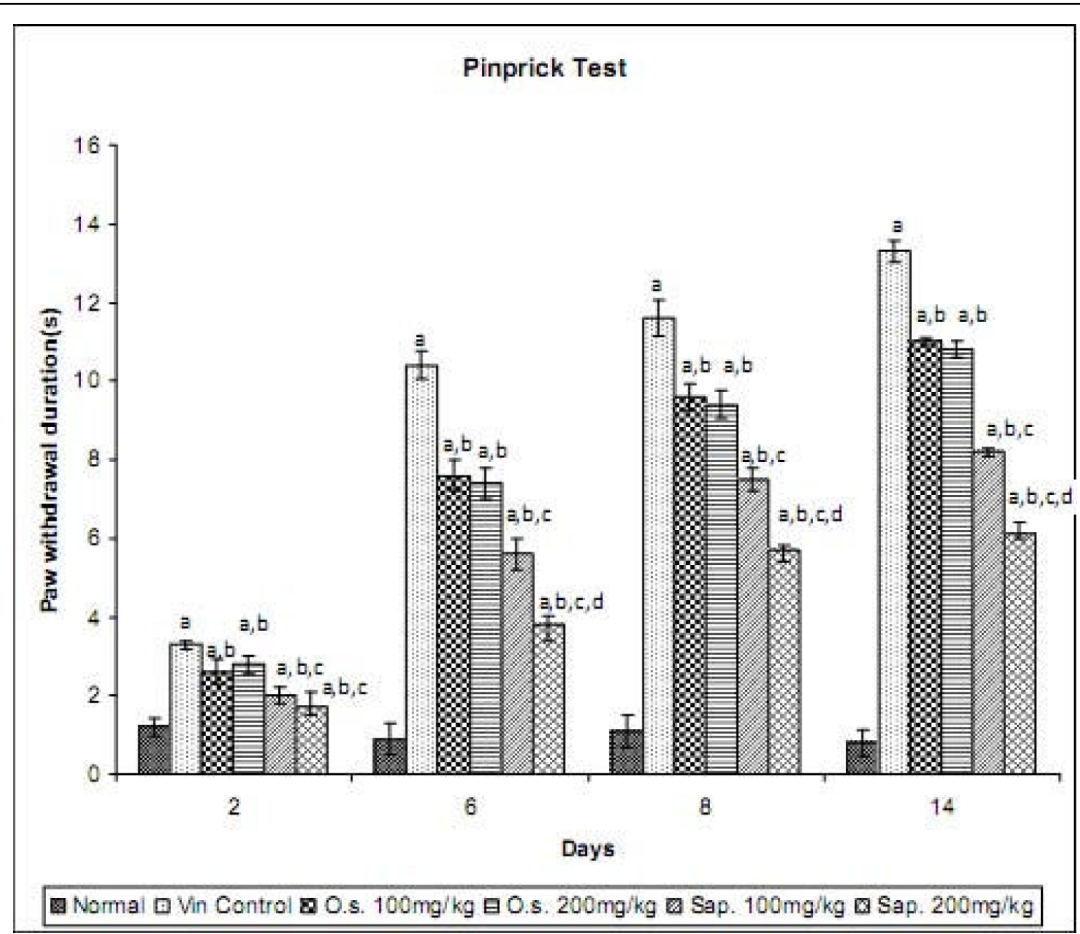

Figure 2 Effect of Ocimum sanctum and its saponin rich fraction on mechanical hyperalgesia in vincristine-induced neuropathic pain. Vin.: vincristine, O.s.: Ocimum sanctum, Sap.: saponin rich extract of Ocimum sanctum. Data were expressed as mean \pm S.E.M., $n=6$ rats per group. $a=p<0.05$ Vs normal control group, $b=p<0.05$ Vs vincristine control group, $c=p<0.05$ Vs Ocimum sanctum 100 and 200 mg/kg group, $d=p<0.05$ Vs saponin rich fraction $100 \mathrm{mg} / \mathrm{kg}$ group.

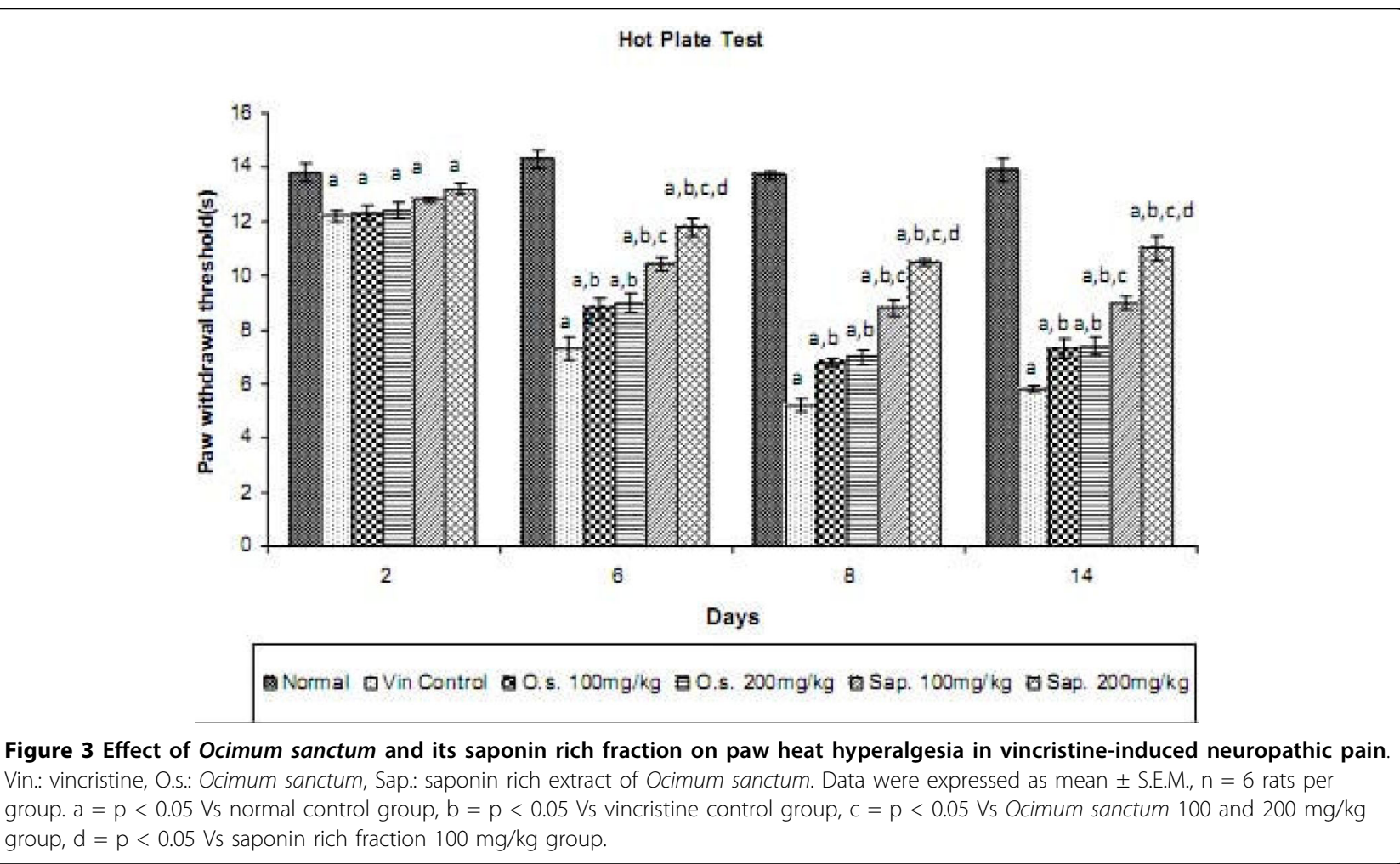




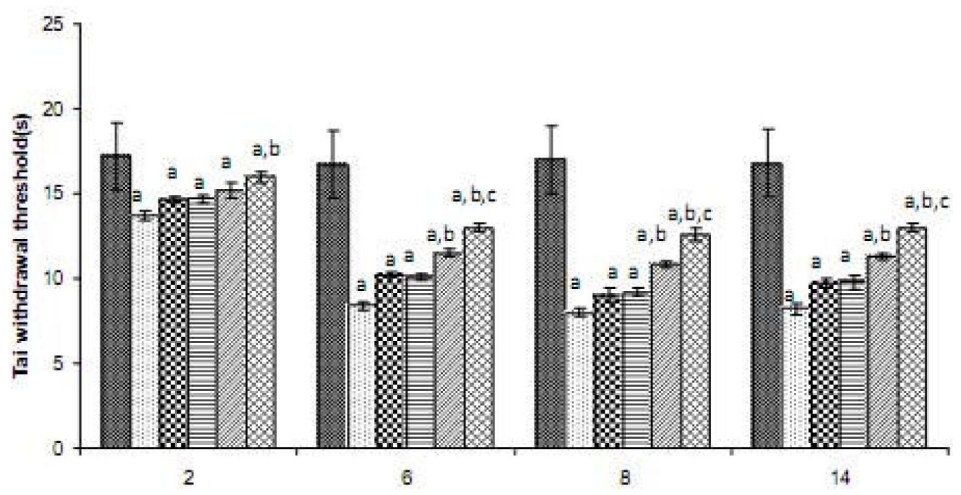

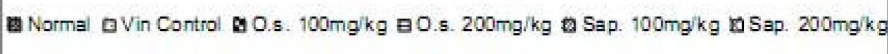

Figure 4 Effect of Ocimum sanctum and its saponin rich fraction on tail cold hyperalgesia in vincristine-induced neuropathic pain. Vin.: vincristine, O.s.: Ocimum sanctum, Sap.: saponin rich extract of Ocimum sanctum. Data were expressed as mean \pm S.E.M., $n=6$ rats per group. a $=p<0.05$ Vs normal control group, $b=p<0.05$ Vs vincristine control group, $c=p<0.05$ Vs Ocimum sanctum 100 and 200 mg/kg group.

attenuated vincristine-induced behavioral alterations in neuropathic pain. Therefore, it may be proposed that saponins are the principal components responsible for the noted beneficial effects of Ocimum sanctum in neuropathic pain.

Furthermore, in this study vincristine administration was associated with the rise in the oxidative stress (rise in thio-barbituric acid reactive substances and superoxide anion content) and total calcium content. It has also been documented that oxidative stress and an increase in calcium levels play a critical role in chemotherapy associated neuropathic pain including vincristine $[28,33,42]$. However, treatment with Ocimum sanctum and its saponin rich fraction attenuated vincristine associated increase in oxidative stress and calcium levels. Ocimum sanctum has a well documented antioxidant effect $[10,43]$ and also decreases the calcium levels [12].

Free radicals have been well documented to increase calcium levels $[44,45]$. Therefore, the observed decrease in calcium levels with Ocimum sanctum may possibly be

Table 2 Effect of Ocimum sanctum and its saponin rich fraction on thio-barbituric acid reactive substances, superoxide anion content and total calcium in vincristine-induced neuropathic pain.

\begin{tabular}{|c|c|c|c|c|c|}
\hline Groups & Doses & $\begin{array}{l}\text { Total Protein } \\
\text { (mg/g of } \\
\text { tissue) }\end{array}$ & $\begin{array}{l}\text { TBARS } \\
\text { ( } \mathrm{nmol} / \mathrm{mg} \text { of } \\
\text { protein) }\end{array}$ & $\begin{array}{l}\text { Superoxide Anion } \\
\text { Content } \\
\text { (pmol/min/mg of protein) }\end{array}$ & $\begin{array}{l}\text { Total Calcium } \\
\text { (ppm/mg of } \\
\text { protein) }\end{array}$ \\
\hline Normal Control & - & $5.17 \pm 0.23$ & $5.97 \pm 0.26$ & $0.15 \pm 0.02$ & $4.97 \pm 0.21$ \\
\hline Vincristine Control & - & $5.36 \pm 0.13$ & $8.28 \pm 0.24^{a}$ & $0.79 \pm 0.05^{a}$ & $32.20 \pm 0.18^{\mathrm{a}}$ \\
\hline Vehicle in Vincristine Control & - & $5.29 \pm 0.17$ & $8.24 \pm 0.22^{a}$ & $0.81 \pm 0.03^{\mathrm{a}}$ & $32.02 \pm 0.16^{\mathrm{a}}$ \\
\hline Ocimum sanctum per se & $\begin{array}{l}200 \mathrm{mg} / \\
\mathrm{kg}\end{array}$ & $5.21 \pm 0.15$ & $6.00 \pm 0.28$ & $0.16 \pm 0.01$ & $5.09 \pm 0.15$ \\
\hline Saponin rich fraction per se & $\begin{array}{l}200 \mathrm{mg} / \\
\mathrm{kg}\end{array}$ & $5.30 \pm 0.14$ & $6.06 \pm 0.24$ & $0.14 \pm 0.02$ & $4.92 \pm 0.17$ \\
\hline Ocimum sanctum in vincristine control & $\begin{array}{l}100 \mathrm{mg} / \\
\mathrm{kg}\end{array}$ & $5.33 \pm 0.22$ & $7.56 \pm 0.16^{a, b}$ & $0.56 \pm 0.02^{a, b}$ & $29.5 \pm 0.18^{a, b}$ \\
\hline Ocimum sanctum in vincristine control & $\begin{array}{l}200 \mathrm{mg} / \\
\mathrm{kg}\end{array}$ & $5.26 \pm 0.16$ & $7.52 \pm 0.15^{a, b}$ & $0.54 \pm 0.03^{\mathrm{a}, \mathrm{b}}$ & $29.8 \pm 0.20^{a, b}$ \\
\hline $\begin{array}{l}\text { Saponin rich fraction in vincristine } \\
\text { control }\end{array}$ & $\begin{array}{l}100 \mathrm{mg} / \\
\mathrm{kg}\end{array}$ & $5.35 \pm 0.13$ & $6.90 \pm 0.19^{a, b, c}$ & $0.38 \pm 0.04^{a, b, c}$ & $21.1 \pm 0.19^{a, b, c}$ \\
\hline $\begin{array}{l}\text { Saponin rich fraction in vincristine } \\
\text { control }\end{array}$ & $\begin{array}{l}200 \mathrm{mg} / \\
\mathrm{kg}\end{array}$ & $5.29 \pm 0.14$ & $6.28 \pm 0.21^{a, b}, c, d$ & $0.25 \pm 0.02^{a, b, c, d}$ & $12.2 \pm 0.13^{a, b, c, c}$ \\
\hline
\end{tabular}

Data were expressed as mean \pm S.E.M., $n=6$ rats per group $a=p<0.05$ Vs normal control group, $b=p<0.05$ Vs vincristine control group, $c=p<0.05$ Vs Ocimum sanctum 100 and $200 \mathrm{mg} / \mathrm{kg}$ group, $\mathrm{d}=\mathrm{p}<0.05 \mathrm{Vs}$ saponin rich fraction $100 \mathrm{mg} / \mathrm{kg}$ group. 
attributed to its antioxidant effects. However, it may also be possible that direct action of Ocimum sanctum is responsible for the observed decrease in the calcium levels. Therefore, the observed decrease in calcium levels due to Ocimum sanctum may be either due to direct action or secondary to decrease in oxidative stress. However, data of the present study is still insufficient to elaborate the precise mechanism of Ocimum sanctum mediated decrease in calcium levels. Furthermore, saponins have also been reported to decrease oxidative stress [46] and calcium levels [47-49]. Based on these, it may be proposed that Ocimum sanctum has potential in ameliorating the painful symptoms in vincristine-induced peripheral neuropathy and saponins may be the principal chemical class responsible for its beneficial effect in neuropathic pain. Furthermore, the pain relieving effects of Ocimum sanctum and its saponin rich fraction may be due to attenuation of nerve injury inciting agent-induced increased levels of calcium and free radicals.

\section{Acknowledgements}

The authors are grateful to Department of Pharmaceutical Sciences and Drug Research, Punjabi University, Patiala, India for supporting this study and providing technical facilities for the work. The authors are also thankful to the Herbal Research Department, Ranbaxy Research Lab, Gurgaon, India for HPTLC studies of Ocimum sanctum.

\section{Authors' contributions}

GK carried out experimental studies including induction of neuropathy, behavioral and biochemical testing. ASJ carried out data analysis including the statistical analysis and participated in critical intellectual discussion and designing of the experiments. NS conceived the idea, coordinated the study, carried our data interpretation and drafted the manuscript. All authors read and approved the final manuscript.

\section{Competing interests}

The authors declare that they have no competing interests.

Received: 29 July 2009

Accepted: 25 January 2010 Published: 25 January 2010

\section{References}

1. Mitchell SW: Injuries of nerves and their consequences. Philadephia; J. B. Lippincott 1872.

2. Woolf CJ, Mannion RJ: Neuropathic pain, aetiology, symptoms, mechanisms and management. Lancet 1999, 353:1959-1964.

3. Werhagen L, Budh CN, Hultling C, Molander C: Neuropathic pain after traumatic spinal cord injury relations to gender, spinal level, completeness, and age at the time of injury. Spinal Cord 2004, 42:665-673.

4. Alston RP, Pechon P: Dysesthesia associated with sternotomy for heart surgery. Br J Anaesth 2005, 95:153-158.

5. Bromberg MB: Peripheral neurotoxic disorders. Clin Neurobehav Toxicol 2000, 18:681-689.

6. Pal PK: Clinical and electrophysiological studies in vincristine induced neuropathy. Electromyogr Clin Neurophysiol 1999, 39:323-330.

7. Kalita J, Vajpayee A, Misra UK: Comparison of prednisolone with piroxicam in complex regional pain syndrome following stroke: a randomized controlled trial. QJM 2006, 99(2):89-95.

8. Yanpallewar SU, Sunita R, Mohan K, Acharya SB: Evaluation of antioxidant and neuroprotective effect of Ocimum sanctum on transient cerebral ischemia and long-term cerebral hypoperfusion. Pharmacol Biochem Behav 2004, 79:155-164.
9. Jaggi RK, Madaan R, Singh B: Anticonvulsant potential of holy basil, Ocimum sanctum Linn., and its cultures. Indian J Exp Biol 2003, 41:1329-1333.

10. de Almeida I, Alviano DS, Vieira DP, Alves PB, Blank AF, Lopes AH, Alviano CS, Rosa MS: Antigiardial activity of Ocimum basilicum essential oil. Parasitol Res 2007, 101:443-452.

11. Bhattacharyya D, Sur TK, Jana U, Debnath PK: Controlled programmed trial of Ocimum sanctum leaf on generalized anxiety disorders. Nepal Med Coll J 2008, 10(3):176-179.

12. Balanehru S, Nagarajan B: Protective effect of oleanolic acid and ursolic acid against lipid peroxidation. Biochem Int 1991, 24:981-990.

13. Anandjiwala S, Kalola J, Rajani M: Quantification of eugenol, luteolin, ursolic acid, and oleanolic acid in black (Krishna Tulasi) and green (Sri Tulasi) varieties of Ocimum sanctum Linn. using high-performance thinlayer chromatography. J AOAC Int 2006, 89:1467-1474.

14. Muthuraman A, Diwan V, Jaggi AS, Singh N, Singh D: Ameliorative effects of Ocimum sanctum in sciatic nerve transection-induced neuropathy in rats. J Ethnopharmacol 2008, 120(1):56-62.

15. Rhiouani H, Settaf A, Lyoussi B, Cherrah Y, Lacaille-Dubois MA, Hassar M: Effects of saponins from Herniaria glabra on blood pressure and renal function in spontaneously hypertensive rats. Therapie 1999, 54(6):735-739.

16. Shibata S: Chemistry and Cancer Preventing Activities of Ginseng Saponins and Some Related Triterpenoid Compounds. J Korean Med Sci 2001, 16:28-37.

17. Pal D, Sahoo M, Mishra AK: Analgesic and anticonvulsant effects of Saponin isolated from the stems of Opunntia vulgaris mill. in mice. Eur Bull Drug Res 2005, 13:91-97.

18. Chen ZH, Li J, Liu J, Zhao Y, Zhang P, Zhang MX, Zhang L: Saponins isolated from the root of Panax notoginseng showed significant antidiabetic effects in KK-Ay mice. Am J Chin Med 2008, 36(5):939-951.

19. Wang LC, Wang B, Ng SY, Lee TF: Effects of ginseng saponins on betaamyloid-induced amnesia in rats. J Ethnopharmacol 2006, 103(1):103-108.

20. Al-Habori M, Raman A: Antidiabetic and hypocholesterolaemic effects of fenugreek. Phytother Res 1998, 12:233-242.

21. Kim JH, Kim S, Yoon IS, Lee JH, Jang BJ, Jeong SM, Lee JH, Lee BH, Han JS, Oh S, Kim HC, Park TK, Rhim H, Nah SY: Protective effects of ginseng saponins on 3-nitropropionic acid-induced striatal degeneration in rats. Neuropharmacology 2005, 48(5):743-756.

22. Moharram FA, El-Shenawy SM: Antinociceptive and anti-inflammatory steroidal saponins from Dracaena ombet. Planta Med 2007, 73(10):1101-1106.

23. Wang J, Zhou H, Jiang Z, Wong Y, Liu L: In Vivo Anti-inflammatory and Analgesic Activities of a Purified Saponin Fraction Derived from the Root of Ilex pubescens. Biol Pharm Bull 2008, 31(4):643-650.

24. Yin X, Zhang Y, Wu H, Zhu X, Zheng X, Jiang S, Zhuo H, Shen J, Li L, Qiu J: Protective effects of Astragalus saponin I on early stage of diabetic nephropathy in rats. J Pharmacol Sci 2004, 95(2):256-266.

25. Liu J, Li Y, Yuan X, Yang Z, Lin Z: Sodium beta-aescin may be an effective therapeutic agent for Bell's palsy. Med Hypotheses 2008, 71(5):762-764.

26. Ebata N, Nakajima K, Hayashi K, Okada M: Maruno Saponins from the root of Bupleurum falcatum. Phytochemistry 1996, 41(3):895-901.

27. Sadraei $H$, Asghari $G$, Hekmatti $A A$ : Antispasmodic effect of three fractions of hydroalcoholic extract of Pycnocycla spinosa. J Ethnopharmacol 2003, 86(2-3):187-190

28. Siau C, Bennett GJ: Dysregulation of neuronal calcium homeostasis in chemotherapy-evoked painful peripheral neuropathy. Anesth Analg 2006, 102:1485-1490.

29. Decosterd I, Woolf CJ: Spared nerve injury: an animal model of persistent peripheral neuropathic pain. Pain 2000, 87:149-158.

30. Jain $\mathrm{V}$, Jaggi $A S$, Singh $\mathrm{N}$ : Ameliorative potential of rosiglitazone in tibial and sural nerve transection-induced painful neuropathy in rats. Pharmacol Res 2009, 59(6):385-392.

31. Erichsen HK, Blackburn-Munro G: Pharmacological characterization of the spared nerve injury model of neuropathic pain. Pain 2002, 98:151-161.

32. Necker $R$, Hellon RF: Noxious thermal input from the rat tail: modulation by descending inhibitory influences. Pain 1978, 4:231-242.

33. Muthuraman A, Jaggi AS, Singh N, Singh D: Ameliorative effects of amiloride and pralidoxime in chronic constriction injury and vincristineinduced painful neuropathy in rats. Eur J Pharmacol 2008, 587:104-111.

34. Lowry OH, Rosenbrough NJ, Farr AL, Randall RJ: Protein measurement with folin phenol reagent. J Biol Chem 1951, 193:265-275. 
35. Okhawa $H$, Ohishi $N$, Yagi K: Assay for lipid peroxidation in animal tissue by thiobarbituric acid reaction. Anal Biochem 1979, 95:351-358.

36. Wang HD, Pagano PJ, Du Y, Cayatte AJ, Quinn MT, Brecher P, Cohen RA: Superoxide anion from the adventitia of the rat thoracic aorta inactivates nitric oxide. Circ Res 1998, 82:810-818.

37. Severinghaus JW, Ferrebee JW: Calcium determination by flame photometry; methods for serum, urine, and other fluids. I Biol Chem 1950, 187:621-630

38. Lu J, Zheng YL, Wu DM, Luo L, Sun DX, Shan Q: Ursolic acid ameliorates cognition deficits and attenuates oxidative damage in the brain of senescent mice induced by D-galactose. Biochem Pharmacol 2007, 74(7):1078-1090

39. Somova LO, Nadar A, Rammanan P, Shode FO: Cardiovascular, antihyperlipidemic and antioxidant effects of oleanolic and ursolic acids in experimental hypertension. Phytomedicine 2003, 10(2-3):115-121.

40. Senthil S, Chandramohan G, Pugalendi KV: Isomers (oleanolic and ursolic acids) differ in their protective effect against isoproterenol-induced myocardial ischemia in rats. Int J Cardiol 2007, 119(1):131-133.

41. Manu KA, Kuttan G: Ursolic acid induces apoptosis by activating p53 and caspase-3 gene expressions and suppressing NF-kappaB mediated activation of bcl-2 in B16F-10 melanoma cells. Int Immunopharmacol 2008, 8(7):974-981.

42. Kamei J, Tamura N, Saitoh A: Possible involvement of the spinal nitric oxide/cGMP pathway in vincristine-induced painful neuropathy in mice. Pain 2005, 117:112-120.

43. George S, Chaturvedi P: Protective role of Ocimum sanctum plant extract in alcohol-induced oxidative stress in albino rats. Br J Biomed Sci 2008 65(2):80-85

44. Doan TN, Gentry DL, Tylor AA, Elliott SJ: Hydrogen peroxide activates agonist-sensitive $\mathrm{Ca}^{2+}$ influx pathways in canine venous endothelial cells. Biochem J 1994, 297:209-215.

45. Kawakami M, Okabe E: Superoxide Anion Radical-Triggered $\mathrm{Ca}^{2+}$ Release from Cardiac Sarcoplasmic Reticulum through Ryanodine Receptor $\mathrm{Ca}^{2+}$ Channel. Mol Pharmacol 1998, 53(3):497-503.

46. Feresin GE, Tapia A, Gutierrez RA, Delporte C, Backhouse Erazo N, SchmedaHirschmann G: Free radical scavengers, anti-inflammatory and analgesic activity of Acaena magellanica. J Pharm Pharmacol 2002, 54(6):835-844.

47. Tao J, Wang H, Zhou H, Li S: The saponin monomer of dwarf lilyturf tuber, DT-13, reduces L-type calcium currents during hypoxia in adult rat ventricular myocytes. Life Sci 2005, 77(24):3021-3030.

48. Li W, Li W, Yin Y, Gong H, Wu G, Zhu F: Protective effects of AST and ASI on memory impairment and its mechanism in senescent rats treated by GC. Zhongguo Zhong Yao Za Zhi 2009, 34(2):199-203.

49. Li Y, Chen X, Liu H, Luo F, Li G: Effects of ginseng total saponins with berberine on plasma brain natriuretic peptide and $\mathrm{Ca}^{2+}$ concentration in experimental rats with chronic congestive heart failure. Zhongguo Zhong Yao Za Zhi 2009, 34(3):324-327.

doi:10.1186/1749-7221-5-3

Cite this article as: Kaur et al:: Exploring the potential effect of Ocimum sanctum in vincristine-induced neuropathic pain in rats. Journal of Brachial Plexus and Peripheral Nerve Injury 2010 5:3.

\section{Submit your next manuscript to BioMed Central and take full advantage of:}

- Convenient online submission

- Thorough peer review

- No space constraints or color figure charges

- Immediate publication on acceptance

- Inclusion in PubMed, CAS, Scopus and Google Scholar

- Research which is freely available for redistribution

Submit your manuscript at www.biomedcentral.com/submit 